\title{
The world through open eyes
}

\section{Donald MacKay}

The Way the World Is: The Christian Perspective of a Scientist. By John Polkinghorne. Triangle: 1983. Pp.130. Pbk $£ 1.85$.

THIS is a refreshing little book. Its author, a distinguished theoretical physicist, is also the only living fellow of the Royal Society in holy orders, and so is eminently qualified to speak for the many practising scientists who find their profession entirely harmonious with their religious commitment, and are puzzled by the persistent notion that the two are incompatible.

What is refreshing is the clean and straight thinking that John Polkinghorne brings to the issue. As a physicist, he has much to say about the revolution in thinking that has overtaken our classical pictures of the physical world. Things are much less clear cut in the world of matter than they were thought to be. But instead of making this a handwaving excuse for lowering our standards of intellectual integrity in matters of religion, he insists that only scrupulous respect for data given facts - can lead us to a realistic view of the way the world is, in its spiritual as well as its physical aspects. Not openminded rationality, but fashion-conscious rationalism - the refusal to give due weight to evidence because of preconceived current ideas of what is "reasonable" - is the enemy here; and on this score Polkinghorne does not hesitate to twist (gently) the tails of some modern theologians (p.ix).

His first three chapters offer an extremely readable introduction to the way our scientific picture of the world is moving. The sense of process, of fresh turns of thought taken almost daily in response to fresh evidence, is well conveyed by examples ranging from cosmology (the big bang, the $3^{\circ} \mathrm{K}$ radiation) and quantum physics to sociobiology. The recognized need for different scientific levels of description of the reality we actually encounter then introduces the main theme of the book, namely, that we miss the whole point of our existence if we do not take seriously enough the religious dimension of reality. The remaining chapters spell out what taking this seriously has meant for John Polkinghorne. Lucidly, with a light touch, he shows how for him an open-eyed commitment to do justice to all the evidence has led to the conviction that "God [has] acted to make himself known ... not in the shadowy figures of mythology ... . but in the concrete historical figure of Jesus of Nazareth"' (p.110). Nontheologians - and non-physicists for that matter - will be helped throughout by an admirable 10-page glossary of scientific and theological terms, which are identified by asterisks as they crop up in the main text.
From a scientific standpoint the outstanding merit of the book lies in the corrective it offers to popular images of science as a spiritually desiccating career:

Wonder at the structure of the world is an authentic part of the scientist's experience. It is the payoff for all those weary hours of study and all the frustrations and disappointments inescapable in the prosecution of research. I believe that [such experiences] are vital to our understanding of the way the world is [p.16].

Again, Polkinghorne makes clear that reductionist methodology does not at all entail reductionist metaphysics, even though sometimes "A questing agnosticism may be the best we can manage" about relationships between different levels of description (p.25). He rightly cautions against using the physical notion of "complementarity" glibly to "explain" such relationships; though unfortunately he fails to distinguish this from the logical concept of hierarchic complementarity, which some would see as essential to a working integration of knowledge we obtain at different levels.

The theological chapters, though quite technical, are attractively laced with humour and commonsense. At one knotty point "we are back", says Polkinghorne, "in that 'astronomical' area of debate where limited data and unlimited human ingenuity can produce a number of answers

\section{Signal understanding}

\section{P.W. Hawkes}

\section{Applications of Optical Fourier}

Transforms.

Edited by Henry Stark

Academic: 1982. Pp.560. \$67.50, £44.60. Optical Information Processing.

By F.T.S. Yu.

Wiley: 1983. Pp.562. £43.50, \$69.75.

THE USE of optical methods to manipulate, sieve, enhance and transmit information is growing so rapidly and attracting so much attention, both academic and industrial, that we must expect a steady flow of textbooks and progress reports during the coming years. The volumes of $\mathrm{Yu}$ and Stark are both very respectable texts, with some points in common, though, unlike Yu's book, Stark's is a multi-author collection.

The strengths and weaknesses of the second approach are well-known but Stark has chosen his collaborators carefully and of varying plausibility" (p.57). On the other hand,

Christianity, by focusing its understanding of the world on a particular man, can no more be independent of history than a theoretical physicist can neglect the findings of his experimental colleagues. Some Christians have felt that this makes faith intolerably contingent upon history. I welcome that contingency [p.40].

The idea that in Christian thought man is "an animated body and not an incarnated soul" 'is usefully spelt out, with the memorably expressed conclusion that "the hope of resurrection is very different from being a fly stuck in the amber of divine thought" (p.92). On the other hand, "One learns pretty soon in science that there are times when problems are ripe for solution and times when they are not'. Detailed speculation in this area, Polkinghorne suggests, is at present a waste of time.

Most of Polkinghorne's own speculative judgements abide fairly by his declared canons. An exception is his slight tendency to follow current fashion in patronising the writers of the New Testament (e.g. on p.86 the Apostle Paul, whose name, oddly enough, is not in the index). But the attractive spirit of the book as a whole is well epitomised in a final quotation, from p.26: "If the study of science teaches one anything, it is that it is unwise to try to lay down beforehand by pure thought what will actually prove to be the case. Reality is often so much more subtle than we imagine",

Donald MacKay, a physicist, is Emeritus Professor of Communication and Neuroscience at Keele University.

succeeded in persuading them to follow his guidelines, so that the result is more homogeneous than in many such collections. Apart from Stark's opening essay on the theory and measurement of the optical Fourier transform, each contribution deals with a specific class of applications. Generally speaking, these separate accounts are very informative and readable.

I was particularly pleased to see that new developments have not been allowed to squeeze out pioneering work. So, for instance, the chapter by Almeida and Indebetouw, on pattern recognition via complex spatial filtering, reminds us of the work of Duffieux, Maréchal and Croce, Elias, Linfoot, Tsujiuchi, O'Neill, Vander Lugt and Lohmann among many others, before turning to more recent developments. The other chapters, all by recognized authorities, cover particle identification and counting, hybrid systems, radar, photographic measurements, SAW devices, space-variance, nonlinear processing, the human visual system, statistical pattern recognition and finally incoherent processing. Anyone wishing to 